\title{
Thermodynamic analysis of electrodeposition of copper from copper sulphate
}

\author{
RUPAYAN GHOSH ${ }^{\mathbf{1}}, \mathrm{V}^{\text {SUDHA }}{ }^{\mathbf{2}}$ and S HARINIPRIYA ${ }^{\mathbf{3}, *(1)}$ \\ ${ }^{1}$ Department of Chemical Engineering, SRM Institute of Science and Technology, Kattankulathur 603203, Chennai, India \\ ${ }^{2}$ Department of Chemistry, SRM Institute of Science and Technology, Kattankulathur 603203, Chennai, India \\ ${ }^{3}$ Electrochemical Systems Lab, SRM Research Institute, SRM Institute of Science and Technology, \\ Kattankulathur 603203, Chennai, India \\ *Author for correspondence (harinipriya.s@ res.srmuniv.ac.in)
}

MS received 10 April 2018; accepted 16 July 2018; published online 12 February 2019

\begin{abstract}
The free energy of activation of copper electrodeposition from copper sulphate solution is derived in terms of the dehydration energy of copper sulphate, hydration number of copper sulphate, solvated work function of the host metal and coordination number of the host metal on which the copper deposition is carried out. The free energy of activation for copper electrodeposition on 31 different host metals had been evaluated. The trend in the free energy of activation on different metals is studied and feasible electrodeposition of copper for appropriate applications had been suggested. The methodology is extended to obtain the exchange current densities for copper electrodeposition on different surfaces of Pt in acid medium and compared with the existing literature.
\end{abstract}

Keywords. Copper sulphate; copper electrodeposition; thermodynamics; free energy of activation; work function.

\section{Introduction}

Due to miniaturization of electronic devices, the need for thin-film materials replacing bulk material becomes inevitable $[1,2]$. Microelectronic devices, solar cells and magnetic devices [3-5] are few applications that utilize thin films. Thin films gained importance in these devices due to their capability to improve electrical, magnetic, optical and mechanical properties that results in the increase of efficiency of the devices. As grain size increases in thin films, resistivity decreases, hardness reduces and stress becomes tensile [6,7]. There are different synthesis routes to develop these thin films and electrodeposition technique is one among them. It has various advantages over other techniques, such as electrodeposition of large number of pure metal and alloys, easy to control via tailoring electrodeposition parameters, low processing temperature, deposits onto complex shapes and the production of non-equilibrium materials that cannot be accessed by traditional processes [8-12].

The electrochemical phase formations are usually associated with the nucleation and growth processes. The 3D nucleation and growth process include many stages: diffusion of ions to the electrode, discharge on its surface with resulting ad atoms, critical nuclei formation, crystal growth and overlap as a result of diffusion and ion discharge on the crystal surface and also rearrangement of ad atoms onto a crystal lattice [13-19]. The competition between the nucleation and growth processes determines the granularity of the deposit [18] and are influenced by the different operating parameters, such as bath composition, $\mathrm{pH}$, bath temperature, over potential, bath additives, etc. [4,20-24].

In the present work, a phenomenological thermodynamic approach is employed to evaluate the free energy of activation and heterogeneous rate constant for electrodeposition of copper on 31 different host metal surfaces from $\mathrm{CuSO}_{4}$ electrolyte solution. The free energy of activation is written in terms of work function of the host metal, coordination number of host metal, dehydration energy of $\mathrm{CuSO}_{4}$, hydration number of $\mathrm{CuSO}_{4}$ in bulk and interface and metal- $\mathrm{Cu}$ bond formation energy. The variation of free energy of activation and the heterogeneous rate constant for copper electrodeposition on various parameters have been evaluated. Calibration graphs for identification of ideal combination of host metal to attain low free energy of activation and high heterogeneous rate constant is identified and discussed. As a proof of concept, the methodology is utilized to calculate the exchange current density of copper deposition on different Pt surfaces in acid medium. 


\section{Methodology}

The free energy of activation for any reaction on a metal/electrolyte interface can be written as $[25,26]$

$$
\Delta G^{\neq}=\frac{w_{\mathrm{r}}+w_{\mathrm{p}}}{2}+\Delta G_{\mathrm{et}}^{\mathrm{s}}
$$

where $w_{\mathrm{r}}$ and $w_{\mathrm{p}}$ are the work terms involved in the transport of the reactant and the product species from bulk of the solution to interface and metal/electrolyte interface to the bulk, respectively. $\Delta G_{\text {et }}^{\mathrm{s}}$ denotes the free energy change involved in the electron transfer from the solvated electrode surface (in the present case, solvent is water) to the reactant species. Equation (1) is the reminiscent of Marcus theory [27].

The work terms for the transport processes can be written via the hydration behaviour of the electrolyte and the electrode surface. The electrolyte molecules diffuse from the bulk of the solution to the reaction zone (metal/electrolyte interface) by progressive shedding of their hydration sheath. In the reaction zone, the electrolyte molecules are almost dehydrated and hence, $w_{\mathrm{r}}$ and $w_{\mathrm{p}}$ can be written as

$$
w_{\mathrm{r}}=\frac{N_{\mathrm{h} \text { inter }}^{\mathrm{r}}}{N_{\mathrm{h} \text { bulk }}^{\mathrm{r}}} \Delta G_{\text {dehyd }}^{\mathrm{r}}
$$

and

$$
w_{\mathrm{p}}=\frac{N_{\mathrm{h} \text { inter }}^{\mathrm{p}}}{N_{\mathrm{h} \text { bulk }}^{\mathrm{p}}} \Delta G_{\mathrm{hyd}}^{\mathrm{p}},
$$

where $N_{\mathrm{h}}^{\mathrm{r}}$ inter and $N_{\mathrm{h} \text { bulk }}^{\mathrm{r}}$ denote the hydration number of the reactant species at the interface and the bulk, respectively. Analogously, $N_{\mathrm{h} \text { inter }}^{\mathrm{p}}$ and $N_{\mathrm{h} \text { bulk }}^{\mathrm{p}}$ are the hydration number corresponding to the product at the interface and bulk, respectively. The ratios $N_{\mathrm{h} \text { inter }}^{\mathrm{r}} / N_{\mathrm{h} \text { bulk }}^{\mathrm{r}}$ and $N_{\mathrm{h} \text { inter }}^{\mathrm{p}} / N_{\mathrm{h} \text { bulk }}^{\mathrm{p}}$ indicate the percentage variation of the hydration number of the reactant and the product species while getting transported from bulk of the solution to the metal/electrolyte interface. $\Delta G_{\text {dehyd }}^{\mathrm{r}}$ and $\Delta G_{\text {hyd }}^{\mathrm{p}}$ represent the dehydration and hydration energy of the reactant and product species, respectively.

The free energy change involved in the electron transfer process depends on the hydration behaviour and work function of the metal electrode under consideration. Thus,

$$
\Delta G_{\mathrm{et}}^{\mathrm{s}}=-\frac{n F \Phi_{\mathrm{M}}^{\mathrm{s}}}{\mathrm{CN}_{\mathrm{M}}},
$$

where $n$ being the number of electrons involved in the process, $F$ denotes the Faraday constant, $\Phi_{\mathrm{M}}^{\mathrm{s}}$ represents the solvated work function of the metal electrode and $\mathrm{CN}_{\mathrm{M}}$ is the coordination number (here the coordination number is a first-step approximation for coverage of copper on metal surface) of the metal electrode. The coordination number quantitatively takes account of the surface anisotropy of the electrode surface. Therefore, the free energy of activation for any electron transfer process at the reaction zone is written as

$$
\Delta G^{\neq}=\frac{N_{\mathrm{h} \text { inter }}^{\mathrm{r}}}{N_{\mathrm{h} \text { bulk }}^{\mathrm{r}}} \Delta G_{\text {dehyd }}^{\mathrm{r}}+\frac{N_{\mathrm{h} \text { inter }}^{\mathrm{p}}}{N_{\mathrm{h} \text { bulk }}^{\mathrm{p}}} \Delta G_{\mathrm{hyd}}^{\mathrm{p}}-\frac{n F \Phi_{\mathrm{M}}^{\mathrm{s}}}{\mathrm{CN}_{\mathrm{M}}} .
$$

Equation (5) is the general equation for electron transfer process, where there exists no adsorption of the product on the electrode surface. Assuming that the process is reversible, product formed on the electrode surface has two ways to proceed with: (i) get oxidized and return back to solution or (ii) irreversibly adsorb onto the metal surface. Equation (5) holds good for case (i); for case (ii), equation (5) is modified as

$$
\begin{aligned}
\Delta G^{\neq}= & \frac{N_{\mathrm{h} \text { inter }}^{\mathrm{r}}}{N_{\mathrm{h} \text { bulk }}^{\mathrm{r}}} \Delta G_{\text {dehyd }}^{\mathrm{r}}+\frac{N_{\mathrm{h} \text { inter }}^{\mathrm{p}}}{N_{\mathrm{h} \text { bulk }}^{\mathrm{p}}} \Delta G_{\mathrm{hyd}}^{\mathrm{p}} \\
& -\frac{n F \Phi_{\mathrm{M}}^{\mathrm{s}}}{\mathrm{CN}_{\mathrm{M}}}+\frac{\Delta G_{\mathrm{M}-\mathrm{p}}^{\mathrm{form}}}{\mathrm{CN}_{\mathrm{M}}},
\end{aligned}
$$

where $\Delta G_{\mathrm{M}-\mathrm{p}}^{\mathrm{form}}$ indicate the free energy of bond formation between the metal electrode ' $M$ ' and the product ' $\mathrm{p}$ '.

\subsection{Free energy of activation for copper deposition from $\mathrm{CuSO}_{4}$}

The electrolyte is $\mathrm{CuSO}_{4}$ and the electron transfer occurs in two steps: first, reduction of $\mathrm{Cu}^{2+}$ to $\mathrm{Cu}^{+}$and second, reduction of $\mathrm{Cu}^{+}$to $\mathrm{Cu}$ atoms on the plane site of the metal electrode. Although the mechanism suggested for copper deposition in the literature [28] is as follows:

$$
\begin{array}{ll}
\mathrm{Cu}^{2+}+\mathrm{e} \Leftrightarrow \mathrm{Cu}^{+} & \text {(fast) } \\
\mathrm{Cu}^{+}+\mathrm{e} \Leftrightarrow \mathrm{Cu} & \text { (slow) }
\end{array}
$$

the work terms involving $\mathrm{Cu}^{+}$ions are not included in the present methodology. (In the present case, the work done by reactants and products are written in terms of the corresponding free energies. As the product of step I is the reactant in step II, any work terms associated with $\mathrm{Cu}^{+}$ will cancel out upon summation. Hence, we have shown only the involvement of $\mathrm{Cu}^{2+}$ and $\mathrm{Cu}$ species in the work terms. Hence, the mechanism assumed by us is not different from Newman et al [28] and is applicable for all metals.) The formed $\mathrm{Cu}$ atoms diffuse on the surface of the electrode and get deposited on the kink, edge and vacancies of the electrode surface. After the insertion of copper atoms into the lattice of the metal electrode (vacancy sites), the copper atoms completely dehydrates. Until then the copper atoms are hydrated, although not completely, but to a lesser extent. The free energy of activation for copper deposition process is visualized as three different steps: (i) the transport of the electrolyte as a molecule to the reaction zone, accounted by the hydration numbers 
and dehydration energies, (ii) the reduction of the electrolyte into $\mathrm{Cu}$ atoms on the plane surface of the electrode via two single electron transfer steps and (iii) surface diffusion of the $\mathrm{Cu}$ atoms to kink, edge and vacancies of the electrode.

The free energy and work term contributions to the free energy of activation for copper deposition on the metal electrode employing $\mathrm{CuSO}_{4}$ as the electrolyte can be written as

$$
w_{\mathrm{CuSO}_{4}}=\frac{N_{\mathrm{h} \mathrm{inter}}^{\mathrm{CuSO}_{4}}}{N_{\mathrm{h} \text { bulk }}^{\mathrm{CuSO}_{4}}} \Delta G_{\text {dehyd }}^{\mathrm{CuSO}_{4}}
$$

and

$$
w_{\mathrm{Cu}}=\frac{N_{\mathrm{h} \text { inter }}^{\mathrm{Cu}}}{N_{\mathrm{h} \text { bulk }}^{\mathrm{Cu}}} \Delta G_{\mathrm{hyd}}^{\mathrm{Cu}},
$$

where $w_{\mathrm{CuSO}_{4}}$ and $w_{\mathrm{Cu}}$ denote the work done by the reactant $\mathrm{CuSO}_{4}$ and the product $\mathrm{Cu}$ to reach the reaction zone from the bulk of the solution and vice versa. The free energy due to the electron transfer process (for $n=2$ ) can be given as

$$
\Delta G_{\mathrm{et}}^{\mathrm{s}}=-\frac{2 F \Phi_{\mathrm{M}}^{\mathrm{s}}}{\mathrm{CN}_{\mathrm{M}}} .
$$

Since there is chemisorption of the $\mathrm{Cu}$ atoms formed on the electrode surface, equation (6) is valid. Hence,

$$
\begin{aligned}
\Delta G^{\neq}= & \frac{N_{\mathrm{h} \mathrm{inter}}^{\mathrm{CuSO}_{4}}}{N_{\mathrm{h} \mathrm{bulk}}^{\mathrm{CuSO}_{4}}} \Delta G_{\text {dehyd }}^{\mathrm{CuSO}_{4}}+\frac{N_{\mathrm{h} \mathrm{inter}}^{\mathrm{Cu}}}{N_{\mathrm{h} \mathrm{bulk}}^{\mathrm{Cu}}} \Delta G_{\mathrm{hyd}}^{\mathrm{Cu}} \\
& -\frac{2 F \Phi_{\mathrm{M}}^{\mathrm{s}}}{\mathrm{CN}_{\mathrm{M}}}+\frac{\Delta G_{\mathrm{M}-\mathrm{Cu}}^{\mathrm{form}}}{\mathrm{CN}_{\mathrm{M}}} .
\end{aligned}
$$

Equation (10) implies the explicit relationship between the hydration behaviour of reactant and product species, nature of metal electrode and the bonding characteristics of the copper atoms on the electrode surface with the free energy of activation of the electrochemical copper deposition process. The insertion of the formed copper atoms in the vacant sites of the electrode surface causes coordination variation in the lattice of the metal electrode which is taken into account via the inclusion of the parameter $\mathrm{CN}_{\mathrm{M}}$ in equations (5 and 10).

Upon revoking the Arrhenius equation, the heterogeneous rate constant can be written as

$$
k_{\mathrm{et}}=C \frac{k_{\mathrm{B}} T}{h} \exp \left(-\frac{\Delta G^{\neq}}{k_{\mathrm{B}} T}\right),
$$

where $C$ is the bulk concentration of the electrolyte, $k_{\mathrm{B}}$ the Boltzmann constant, $T$ the temperature and $h$ the Planck's constant.

\section{Results and discussion}

From equation (10), by employing parameters such as the concentration to be $6.023 \times 10^{-5}$ molal, dehydration energy for $\mathrm{CuSO}_{4}\left(\Delta G_{\text {dehyd }}^{\mathrm{CuSO}_{4}}\right)$ as $712 \mathrm{~kJ} \mathrm{~mol}^{-1}$, hydration number for $\mathrm{CuSO}_{4}$ at bulk $\left(N_{\mathrm{h} \text { bulk }} \mathrm{CuSO}_{4}\right)$ to be 671 , at interface $\left(N_{\mathrm{h} \text { inter }}^{\mathrm{CuSO}_{4}}\right)$ being 346 , the free energy of activation $\left(\Delta G^{\neq}\right)$for copper electrodeposition on 31 different host metals at room temperature is calculated. The obtained free energy of activation is provided in table 1. From equation (11), the heterogeneous rate constant is calculated for the process and tabulated in table 1 .

\subsection{Dependence of free energy of activation on metal-copper formation energy}

Figure 1 shows the variation of free energy of activation with the $\mathrm{M}-\mathrm{Cu}$ bond formation energy, as this parameter determines the stability of the coatings. From figure 1, it is clear that the variation of $\Delta G^{\neq}$with $\Delta G_{\mathrm{M}-\mathrm{Cu}}^{\text {form }}$ to be linear as suggested in equation (10). The linear fitting of the plot leads to

$$
\Delta G^{\neq}=0.12 \Delta G_{\mathrm{M}-\mathrm{Cu}}^{\mathrm{form}}+3900 .
$$

Upon comparing equations (10 and 12), the physical significance of slope and intercept can be written from the following terms:

$$
\text { Slope: } \frac{1}{\mathrm{CN}_{\mathrm{M}}}
$$

and

$$
\text { Intercept: } \frac{N_{\mathrm{h} \text { inter }}^{\mathrm{CuSO}_{4}}}{N_{\mathrm{h} \text { bulk }}^{\mathrm{CuSO}}} \Delta G_{\mathrm{dehyd}}^{\mathrm{CuSO}_{4}}+\frac{N_{\mathrm{h} \text { inter }}^{\mathrm{Cu}}}{N_{\mathrm{h} \text { bulk }}^{\mathrm{Cu}}} \Delta G_{\mathrm{hyd}}^{\mathrm{Cu}}-\frac{2 F \Phi_{\mathrm{M}}^{\mathrm{s}}}{\mathrm{CN}_{\mathrm{M}}} \text {. }
$$

Thus, slope represents the electrodeposition of $\mathrm{Cu}$ dependence on the coordination number of the host metal. $\mathrm{CN}_{\mathrm{M}}$ represents the number of atoms of $\mathrm{Cu}$ that can be deposited on a lattice site (analogous to surface coverage $\theta$ ). Whereas the intercept is the summation of all hydration terms of $\mathrm{CuSO}_{4}, \mathrm{Cu}$ and the solvated work function of the host metal. Thus, any change in the solvation characteristics of the electrolyte and electrode will be reflected in the intercept. Therefore, for any host metal, the free energy of activation can be deduced with the help of figure 1 and equation (12). Figure 1 can act as a calibration curve to pick and choose the host metal for copper electrodeposition depending upon its application.

\subsection{Variation of free energy of activation for copper electrodeposition with work function of host metal}

Figure 2 implies that the variation of free energy of activation for copper electrodeposition with the work function of host metal to be complex. Depending on the physical state of the metal, the free energy of activation for the process varies. Tantalum being the reactive metal, forms oxide on the surface and 
Table 1. Free energy of activation for copper electrodeposition on 31 different metals at room temperature at $6.023 \times 10^{-5}$ molal concentration with dehydration energy of $712 \mathrm{~kJ} \mathrm{~mol}^{-1}$. The hydration number for $\mathrm{CuSO}_{4}$ at bulk is 671 and at interface is 346 .

\begin{tabular}{|c|c|c|c|c|c|}
\hline Metal & Work function $(\mathrm{eV})$ & $\begin{array}{l}\text { Coordination } \\
\text { number }\end{array}$ & $\begin{array}{l}\text { Metal-Cu bond formation } \\
\text { energy }\left(\mathrm{kJ} \mathrm{mol}^{-1}\right)\end{array}$ & $\begin{array}{c}\text { Free energy of } \\
\text { activation }\left(\mathrm{kJ} \mathrm{mol}^{-1}\right)\end{array}$ & $\begin{array}{c}\text { Heterogeneous rate } \\
\text { constant }\left(\mathrm{mol} \mathrm{cm}^{-3} \mathrm{~s}^{-1}\right)\end{array}$ \\
\hline $\mathrm{Zn}$ & 3.63 & 6 & 412 & 454.56 & $4.71 \times 10^{-18}$ \\
\hline $\mathrm{Tl}$ & 3.84 & 8 & 198 & 414.74 & $4.49 \times 10^{-11}$ \\
\hline $\mathrm{Hg}$ & 3.9 & 6 & 202 & 418.08 & $1.17 \times 10^{-11}$ \\
\hline Mn & 3.9 & 6 & 159 & 410.92 & $2.11 \times 10^{-10}$ \\
\hline $\mathrm{Cd}$ & 4.08 & 6 & 305 & 434.26 & $1.70 \times 10^{-14}$ \\
\hline In & 4.08 & 8 & 247 & 420 & $5.64 \times 10^{-12}$ \\
\hline $\mathrm{Bi}$ & 4.1 & 8 & 289.5 & 425.11 & $6.83 \times 10^{-13}$ \\
\hline $\mathrm{Ti}$ & 4.1 & 8 & 381 & 436.55 & $6.75 \times 10^{-15}$ \\
\hline $\mathrm{Sn}$ & 4.15 & 8 & 401.3 & 438.88 & $2.63 \times 10^{-15}$ \\
\hline $\mathrm{Pb}$ & 4.18 & 8 & 177 & 410.72 & $2.28 \times 10^{-10}$ \\
\hline $\mathrm{Nb}$ & 4.2 & 8 & 177 & 410.64 & $2.35 \times 10^{-10}$ \\
\hline $\mathrm{Ta}$ & 4.22 & 8 & 811.21 & 489.84 & $3.09 \times 10^{-24}$ \\
\hline $\mathrm{Ga}$ & 4.25 & 8 & 138 & 405.56 & $1.83 \times 10^{-9}$ \\
\hline $\mathrm{Ag}$ & 4.3 & 2 & 176 & 423.2 & $1.48 \times 10^{-12}$ \\
\hline Mo & 4.3 & 6 & 197 & 415.06 & $3.95 \times 10^{-11}$ \\
\hline $\mathrm{Cr}$ & 4.4 & 6 & 155 & 407.51 & $8.31 \times 10^{-10}$ \\
\hline $\mathrm{Sb}$ & 4.55 & 8 & 277.4 & 421.76 & $2.65 \times 10^{-12}$ \\
\hline $\mathrm{W}$ & 4.55 & 8 & 305 & 425.21 & $6.58 \times 10^{-13}$ \\
\hline $\mathrm{Fe}$ & 4.65 & 8 & 172 & 408.17 & $6.37 \times 10^{-10}$ \\
\hline Co & 4.7 & 8 & 162 & 406.72 & $1.15 \times 10^{-9}$ \\
\hline $\mathrm{Cu}$ & 4.7 & 6 & 202 & 413.71 & $6.82 \times 10^{-11}$ \\
\hline $\mathrm{Ru}$ & 4.71 & 8 & 397 & 436.05 & $8.27 \times 10^{-15}$ \\
\hline $\mathrm{Re}$ & 4.72 & 6 & 280 & 426.6 & $3.75 \times 10^{-13}$ \\
\hline $\mathrm{Ni}$ & 4.73 & 4 & 206 & 418.44 & $1.01 \times 10^{-11}$ \\
\hline $\mathrm{Al}$ & 4.78 & 6 & 216 & 415.6 & $3.17 \times 10^{-11}$ \\
\hline $\mathrm{Au}$ & 4.78 & 4 & 232 & 424.53 & $8.63 \times 10^{-13}$ \\
\hline Os & 4.83 & 8 & 198 & 410.68 & $2.31 \times 10^{-10}$ \\
\hline $\mathrm{Ir}$ & 4.97 & 8 & 352 & 429.36 & $1.23 \times 10^{-13}$ \\
\hline $\mathrm{Rh}$ & 4.98 & 6 & 395 & 444.34 & $2.91 \times 10^{-16}$ \\
\hline $\mathrm{Pd}$ & 5.01 & 6 & 234 & 417.35 & $1.57 \times 10^{-11}$ \\
\hline $\mathrm{Pt}$ & 5.03 & 8 & 478 & 444.86 & $2.36 \times 10^{-16}$ \\
\hline
\end{tabular}

hence its free energy of activation is the highest amongst the host metals considered in the present work. On the other hand, remaining d block metals (transition metals), such as Fe, Co, $\mathrm{Ni}, \mathrm{Au}, \mathrm{Ag}, \mathrm{Pt}, \mathrm{Pd}, \mathrm{Rh}$, etc. show lower free energy of activation than the reactive tantalum. From figure 2, the experiments involving copper electrodeposition can be designed based on the free energy of activation variation with host metal work function. The combination of low $\Delta G^{\neq}$with $\Phi_{\mathrm{M}}$ of the host metal can be identified from figure 2 and that can be utilized for easy and facile electrodeposition of copper depending on its applications.

\subsection{Variation of free energy of activation with coordination number of the host metals}

From equation (10), it is clear that as the coordination number increases, the free energy of activation for copper electrodeposition decreases. This decrease in free energy of activation with increase in coordination number could be attributed to the inverse proportionality of $\mathrm{CN}_{\mathrm{M}}$ in equation (10) to $\Delta G^{\neq}$. Thus, as coordination number increases, the effect of the host metal on the electrodeposition process decreases and consequently the energetic solvation predominates. Therefore, for metals, such as $\mathrm{Zn}, \mathrm{Mn}, \mathrm{Cd}, \mathrm{Hg}$ and Mo, copper electrodeposition is fairly feasible upon comparison with rest of the host metals considered in the present work (figure 3 ).

\subsection{Trend in the variation of heterogeneous rate constant with metal-copper bond formation energy}

As suggested by equations (10 and 12), the heterogeneous rate constant depends on the $\mathrm{M}-\mathrm{Cu}$ bond formation energy exponentially. As the $\mathrm{M}-\mathrm{Cu}$ bond formation energy increases, the $k_{\text {et }}$ varies from $10^{-9}$ to $10^{-18} \mathrm{~mol} \mathrm{~cm}^{-3} \mathrm{~s}^{-1}$, thus indicating the fact that the host metals with lower $\mathrm{M}-\mathrm{Cu}$ bond formation 


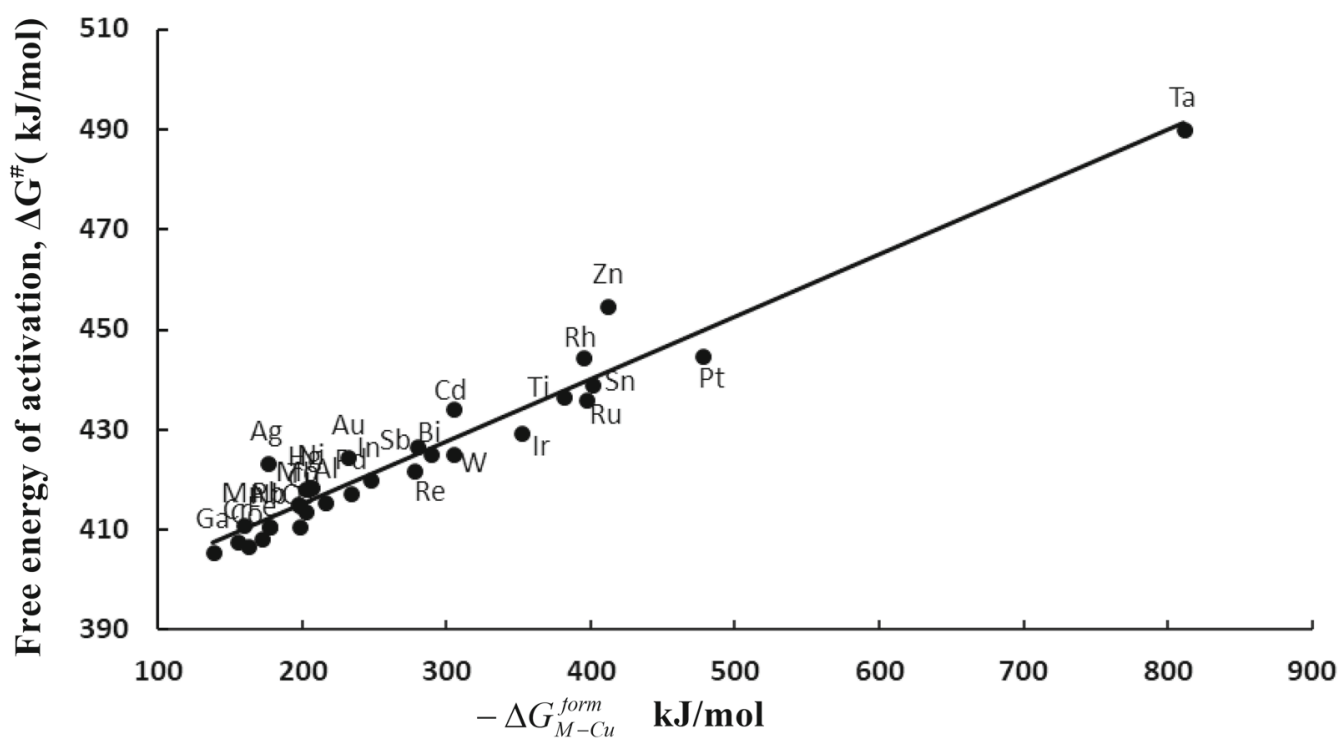

Figure 1. Dependency of $\Delta G^{\neq}\left(\mathrm{kJ} \mathrm{mol}^{-1}\right)$ with $\Delta G_{\mathrm{M}-\mathrm{Cu}}^{\mathrm{form}}\left(\mathrm{kJ} \mathrm{mol}^{-1}\right)$.

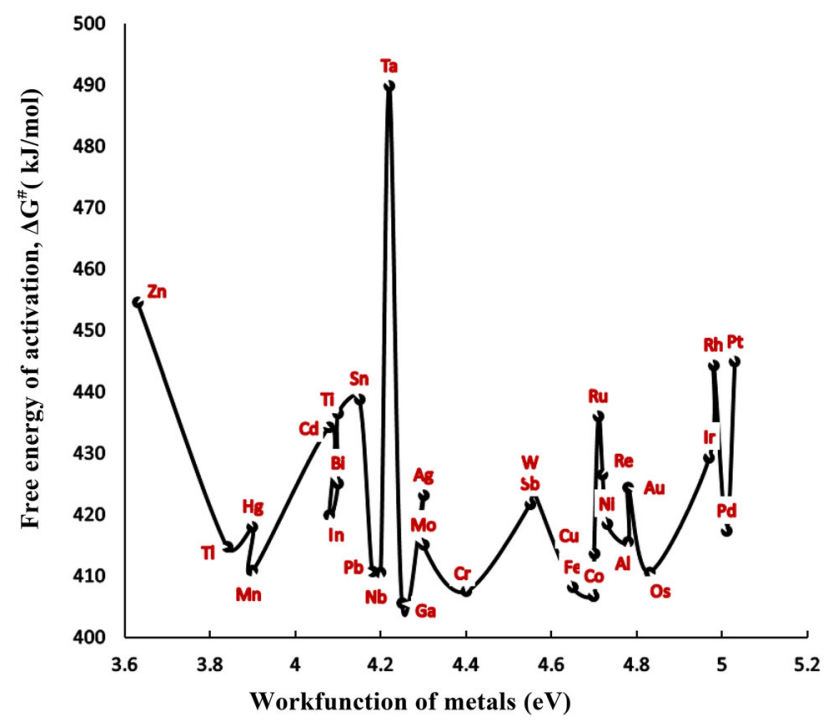

Figure 2. Plot of work function of various metals with the activation energy of $\mathrm{Cu}$ electrodeposition.

energy will possess higher heterogeneous rate for copper electrodeposition. Thus, figure 4 can help the experimentalists to identify the host metal with higher heterogeneous rate constant for copper electrodeposition and hence, can be useful to design the experiment for the required specific applications.

\subsection{Effect of work function of host metal on the heterogeneous rate constant of copper electrodeposition}

Figure 5 implies complex trend and dependency of heterogeneous rate constant of copper electrodeposition with work function of host metal. As discussed in section 3.2, the

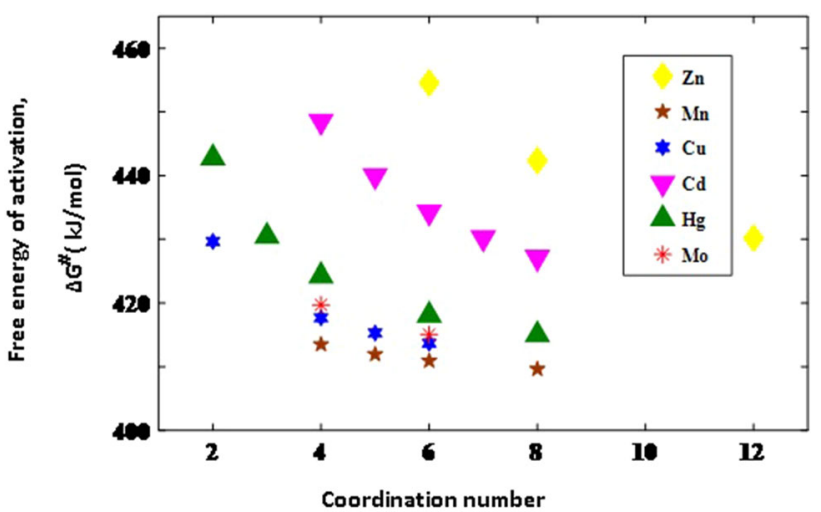

Figure 3. Trend in free energy of activation with coordination number of the host metal.

free energy of activation is very high for Ta and hence, the rate of deposition of copper will be very low. Thus, Ta possesses a heterogeneous rate constant of the order $10^{-18} \mathrm{~mol} \mathrm{~cm}^{-3} \mathrm{~s}^{-1}$. Analogously, metals belonging to the d-block in the Periodic Table, such as $\mathrm{Au}, \mathrm{Ag}, \mathrm{Pt}, \mathrm{Pd}, \mathrm{Rh}, \mathrm{Zn}, \mathrm{Fe}, \mathrm{Co}$, etc. possess lower free energy of activation and higher heterogeneous rate constants.

\subsection{Effect of coordination number of host metal on the heterogeneous rate constant}

From figure 6, it can be inferred that as the coordination number increases, the heterogeneous rate constant increases. Equation (10) indicates that as the coordination number increases, the contribution by host metal work function and $\mathrm{M}-\mathrm{Cu}$ bond formation on the free energy of activation decreases. This makes the solvation effects predominant 


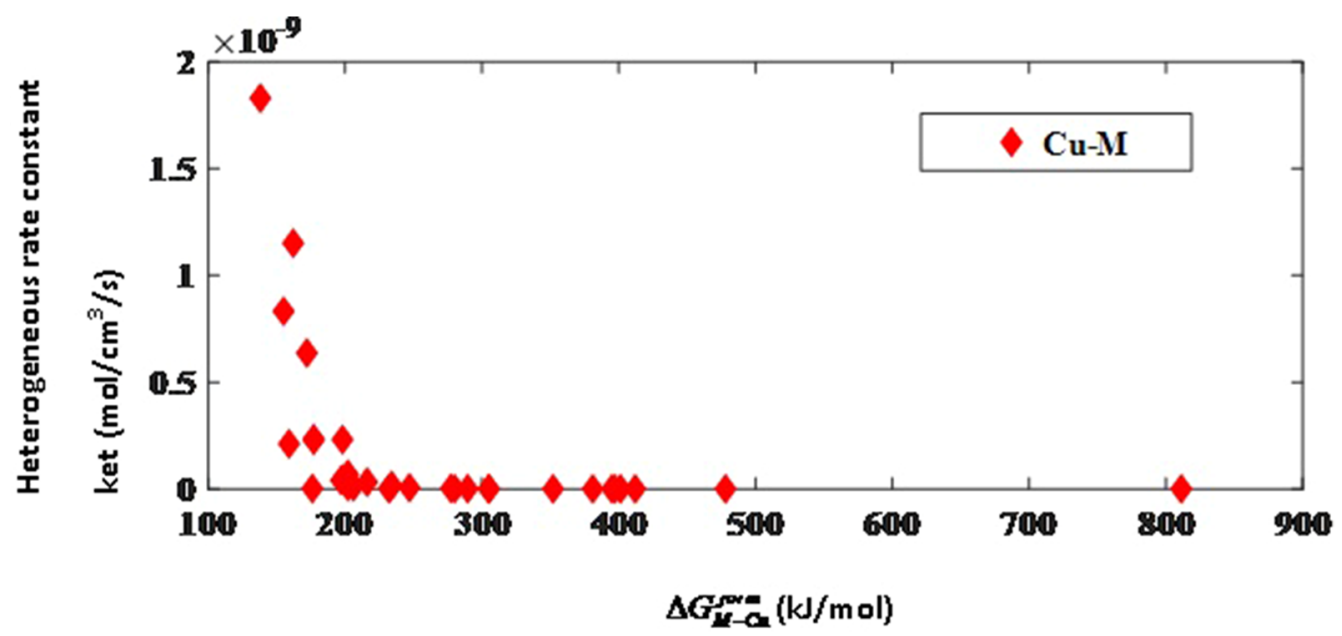

Figure 4. Dependency with $\mathrm{M}-\mathrm{Cu}$ bond formation energy.

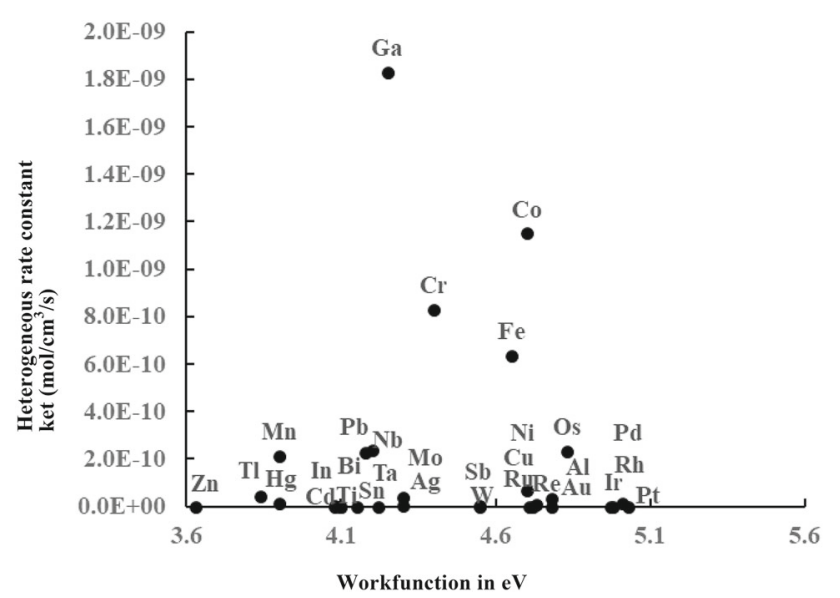

Figure 5. Variation of heterogeneous rate constant with work function of host metal.

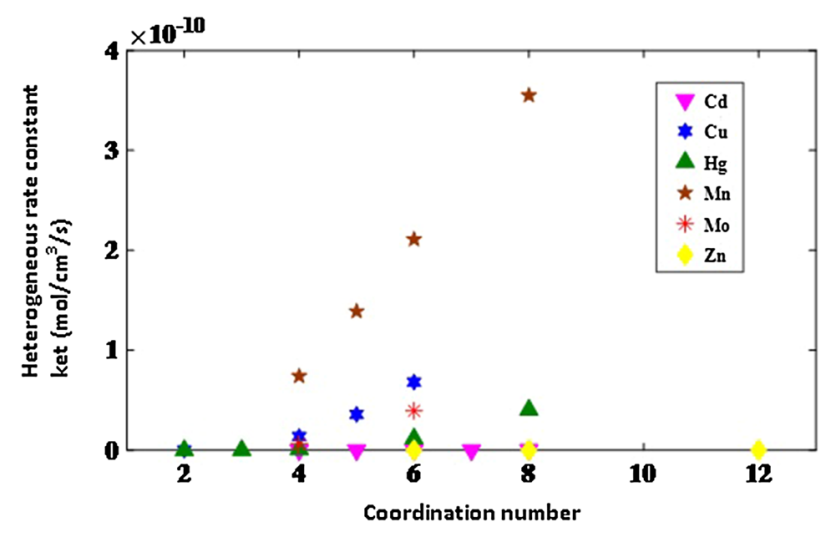

Figure 6. Effect of coordination number of the host metal on the heterogeneous rate constant.

at higher coordination numbers. Host metals with higher coordination numbers, such as $\mathrm{Zn}, \mathrm{Cd}, \mathrm{Mn}, \mathrm{Mo}$ and $\mathrm{Hg}$ will possess higher heterogeneous rate constant for copper electrodeposition on their surfaces. Higher coordination number leads to more vacant sites on the surface, hence, feasibility of copper electrodeposition is very high. In general, electrodeposition initiates on the voids or vacant sites or defects of the host metal, thus, increase in coordination number increases the rate of the electrodeposition.

\subsection{Modified free energy of activation for copper electrodeposition from $\mathrm{CuSO}_{4}$ in acidic medium}

In general, copper electrodeposition experiments were carried out in the literature from the $\mathrm{CuSO}_{4}$ electrolyte on polycrystalline and single-crystal platinum surfaces in acidic medium [29-33]. Hence, the above discussed mechanism to evaluate the electrode kinetics will not be applicable. Therefore, equation (10) is modified as below:

$$
\begin{aligned}
\Delta G^{\neq}= & \frac{N_{\mathrm{h} \mathrm{inter}}^{\mathrm{CuSO}_{4}}}{N_{\mathrm{h} \text { bulk }}^{\mathrm{CuSO}}} \Delta G_{\mathrm{dehyd}}^{\mathrm{CuSO}_{4}}+\frac{N_{\mathrm{h} \text { inter }}^{\mathrm{Cu}}}{N_{\mathrm{h} \text { bulk }}^{\mathrm{Cu}}} \Delta G_{\mathrm{hyd}}^{\mathrm{Cu}} \\
& -2 \theta F \Phi_{\mathrm{M}}^{\mathrm{s}}+\theta \Delta G_{\mathrm{M}-\mathrm{Cu}}^{\mathrm{form}},
\end{aligned}
$$

where the assumed coordination number is replaced by surface coverage ' $\theta$ '. The calculated $\Delta G^{\neq}$from equation (13) is substituted in equation (11) to obtain the rate of reaction. Analogously, the exchange current density reported in the literature can be compared with the values calculated from equation (14) as follows:

$$
i_{0}=\frac{n F k_{\mathrm{et}}}{C A}
$$

where $C$ is the bulk concentration of $\mathrm{CuSO}_{4}$ in $\mathrm{mol} \mathrm{cm}{ }^{-3}$ and $A$ is the area of the electrode in $\mathrm{cm}^{2}$. The calculated $i_{0}$ from equation (14) is in satisfactory agreement with the literature (table 2) thereby supporting the assumptions made 
Table 2. Comparison of the exchange current densities calculated using equation (14) for copper deposition in acidic medium on different $\mathrm{Pt}$ surfaces with the reported values. $\mathrm{Pt}-\mathrm{Cu}$ alloy formation energy is taken as $-27 \mathrm{~kJ} \mathrm{~mol}^{-1}$ from ref. [45].

\begin{tabular}{|c|c|c|c|c|c|c|c|}
\hline \multirow[b]{2}{*}{ Metal surface } & \multirow[b]{2}{*}{$\begin{array}{l}\text { Work function } \\
(\mathrm{eV})\end{array}$} & \multirow[b]{2}{*}{$\begin{array}{c}\text { Area of electrode } \\
\left(\mathrm{cm}^{2}\right)\end{array}$} & \multicolumn{2}{|c|}{ Concentration (M) } & \multirow[b]{2}{*}{$\begin{array}{c}\text { Surface } \\
\text { coverage, } \theta\end{array}$} & \multirow[b]{2}{*}{$i_{0}\left(\mathrm{~mA} \mathrm{~cm}^{-2}\right)$} & \multirow[b]{2}{*}{$\begin{array}{c}i_{0 \_} \text {total (reported) } \\
\left(\mathrm{mA} \mathrm{cm}^{-2}\right)\end{array}$} \\
\hline & & & $\mathrm{CuSO}_{4}$ & $\mathrm{H}_{2} \mathrm{SO}_{4}$ & & & \\
\hline $\mathrm{Pt}$ & 5.03 & 0.1256 [29] & 0.02 & 0.5 & 0.198 & 3.10 & 3.2 [29] \\
\hline \multirow[t]{3}{*}{$\operatorname{Pt}(111)$} & $6.10[41]$ & $0.2826[43]$ & 0.01 & 0.05 & 0.98 & $8.68 \times 10^{-5}$ & $0.01[32]$ \\
\hline & & & 0.025 & 0.05 & 0.40 & 0.0018 & $0.012[32]$ \\
\hline & & & 0.05 & 0.05 & 0.18 & 0.0144 & 0.015 [32] \\
\hline $\operatorname{Pt}(955)$ & $6.25[42]$ & $0.074[44]$ & $2 \times 10^{-4}$ & 0.5 & 0.43 & 0.0041 & $0.006[33]$ \\
\hline $\operatorname{Pt}(544)$ & $6.80[42]$ & $0.076[44]$ & $2 \times 10^{-4}$ & 0.5 & 0.4 & 0.0044 & $0.003[33]$ \\
\hline $\operatorname{Pt}(322)$ & $5.93[42]$ & $0.074[44]$ & $2 \times 10^{-4}$ & 0.5 & 0.46 & 0.0096 & $0.008[33]$ \\
\hline
\end{tabular}

to derive the free energy of activation. It is noted that upon diluting the $\mathrm{CuSO}_{4}$ solution, hydrogen evolution kinetics predominates over copper deposition kinetics and this observation is in agreement with the experimental conclusions (supplementary figure $\mathrm{S} 1$ ).

\section{Conclusions}

It is a known fact that the copper deposits obtained at high-current densities and overpotentials are technologically important [34]. Copper deposits with open and porous structures obtained at high-current densities are used as electrodes in electrochemical devices [34,35], such as fuel cells, batteries and chemical sensors, whereas those of high-surface area are appropriate for evaluating electrochemical reactions such as nitrate ion reduction [36] and for the reaction in which nitrate is reduced to ammonia (high yield) in the presence of aqueous acidic perchlorate and sulphate media [37]. As the dimensions of copper structures continue to scale down into the nanometre range, the initial stage of copper electroformation, i.e., nucleation becomes increasingly important [38]. The foregoing analysis has provided a simple framework whereby the energetics involved in the electrodeposition of copper can be computed efficiently. Several parameters such as the extent of variation of hydration numbers, coordination number, work function and dehydration energy are introduced and expressed parametrically in conjunction with intuitive chemical principles. In the present study, the formalism has been found to be valid for copper deposition from $\mathrm{CuSO}_{4}$ solutions and several subtle features regarding the importance of using these electrolytes in the rate of reaction are pointed out. However, it can be reiterated that this formalism is essentially of a complementary nature to the existing literature $[16,29-33,39,40]$ on electrodeposition of copper. The methodology itself is novel and different from other models reported in the literature. Metallic parameters like effect of anisotropy, porosity of the electrode can be included with significant variation in the present methodology by introducing (i) time dependency, (ii) connecting the free energy of activation to the flux via expression involving $\mathrm{d} c / \mathrm{d} x$, thermodynamic force, etc. as a future improvement in the methodology.

\section{Acknowledgements}

We acknowledge SRM Institute of Science and Technology for providing necessary computational facilities to carry out this work. We also acknowledge the valuable comments of the reviewer.

\section{References}

[1] Mararka S P and Gutmann R J 1993 Thin Solid Films 236257

[2] Lane M W, Murray C E, McFeely F R, Vereecken P M and Rosenberg R 2003 Appl. Phys. Lett. 832330

[3] Zhang J M, Xu K W and Ji V 2002 Appl. Surf. Sci. 18760

[4] Anderson J C 1972 Thin Solid Films 121

[5] Granneman E H A 1993 Thin Solid Films 2281

[6] Yin K B, Xia Y D, Chan C Y and Zhang W Q 2008 Scr. Mater. 5865

[7] Harper M E, Cabra C, Andricacos P C, Gignac L and Noyan I C 1999 J. Appl. Phys. 862516

[8] Wang H, Huang Y, Tan Z and Hu X 2004 Anal. Chim. Acta 526 13

[9] Podaha E J 2004 Nano Lett. 1413

[10] Ibanez A and Fatas E 2005 Surf. Coat. Technol. 1917

[11] Wijesundera R P, Hidaka M, Koga K, Sakai M and Siripala W 2006 Thin Solid Films $\mathbf{5 0 0} 241$

[12] Chatterjee A P, Mukhopadhyay A K, Chakraborty A K, Sasmal R N and Lahiri S K 1991 Mater. Lett. 11358

[13] Mirkin M V and Nilov A P 1990 J. Electroanal. Chem. 28335

[14] Ratsch C and Venables J A 2003 J. Vac. Sci. Technol. A 21 S96

[15] Schmelzer J W P 2001 J. Colloid Interface Sci. 242354

[16] Grujicic D and Pesic B 2002 Electrochim. Acta 472901

[17] Venables J A, Spiller G D T and Hanbucken M 1984 Rep. Prog. Phys. 47399

[18] Budevski E, Staikov G and Lorenz W 2000 Electrochim. Acta 452559

[19] Scarifker B and Hills G 1983 Electrochim. Acta 28879

[20] Zainal Z, Kassim A, Hussein M Z and Ching C H 2004 Mater. Lett. 582199

[21] Fenineche N, Coddet C and Saida A 1990 Surf. Coat. Technol. 4175

[22] Dulal S M S I, Yun H J, Shin C B and Kim C K 2007 Electrochim. Acta $\mathbf{5 3} 934$ 
[23] Ruiz A M, Pardave M P and Batina N 2008 Electrochim. Acta 532115

[24] Ramirez C, Arce E M, Romo M and Pardave M P 2004 Solid State Ionics 16981

[25] Harinipriya S and Subramaniam V R 2008 J. Phys. Chem. B 1124036

[26] Harinipriya S and Sangaranarayanan M V 2002 Langmuir 18 5572

[27] Marcus R A 1956 J. Chem. Phys. 24966

[28] Newman J and Alyea T K 2004 Electrochemical systems, chap 8, 3rd edn (New York: Wiley) p 207

[29] Bozzini B, Mele C and D'urzo L 2006 J. Appl. Electrochem. 3687

[30] Bozzini B, D'urzo L, Re M and De Richardis F 2008 J. Appl. Electrochem. 381561

[31] Bozzini B and Sgura I 2006 J. Appl. Electrochem. 36 983

[32] Markovic N M, Gasteiger H A and Ross P N Jr 1995 Langmuir 114098

[33] Nishihara C, Raspini I A, Kondho H, Shindo H, Kaise M and Nozoye H 1992 J. Electroanal. Chem. 338299
[34] Nikolic N D, Popov K I, Pavlovic L J and Pavlovic M G 2007 Sensors 71

[35] Cheol S H, Dong J and Liu M 2003 Adv. Mater. 151610

[36] Dima G E, de Vooys A C A and Koper M T M 2003 J. Electroanal. Chem. 15554

[37] Pletcher D and Poorbedi Z 1979 Electrochim. Acta 24 1253

[38] Grujicic D and Pesic B 2005 Electrochim. Acta 504426

[39] Li X, Drews T O, Rusli E, Xue F, He Y, Braatz R D et al 2007 J. Electrochem. Soc. 154 D230

[40] Rusli E, Xue F, Drews T O, Vereecken P, Andracacos P, Deligianni $\mathrm{H}$ et al 2007 J. Electrochem. Soc. 154 D584

[41] Derry D N and Zhong Z J 1989 Phys. Rev. B 391940

[42] Buso-Rogero C, Herrero E, Bandlow J, Comas Vives A and Jacob T 2013 Phys. Chem. Chem. Phys. 1518671

[43] Markovic N M, Gasteiger H A and Ross P N Jr 1995 J. Phys. Chem. 993411

[44] Nishihara C and Nozoye H 1995 J. Electroanal. Chem. 386 75

[45] Schroder U, Linke R, Boo J-H and Wnadelt K 1996 Surf. Sci. 352-354 211 